\title{
Potential influence of parental copy number variations on noninvasive prenatal testing (NIPT): two case reports
}

Yiming $\mathrm{Qi}^{1,2+}$, Jiexia Yang ${ }^{1,2+}$, Yaping Hou ${ }^{1,2}$, Rong Hu${ }^{1,2}$, Dongmei Wang ${ }^{1,2}$, Haishan Peng ${ }^{1,2}$ and Aihua Yin ${ }^{1,2^{*}}$

\begin{abstract}
Background: Small subchromosomal deletions and duplications caused by copy number variants (CNVs) can now be detected with noninvasive prenatal testing (NIPT) technology. However, the clinical utility and validity of this screening for CNVs are still unknown. Here, we discuss some special conditions in which both cases simultaneously exhibited false positives caused by maternal CNVs and false negatives due to limitations of the technology.

Case presentation: In case 1, NIPT indicated a 1.1 Mb deletion at 21q21.1, but the umbilical cord for array CGH (aCGH) revealed a $422 \mathrm{~kb}$ deletion at 15q13.3. Peripheral blood of the parents for aCGH showed a $1.1 \mathrm{Mb}$ deletion at 21q21.1 in the mother's sample, and the same deletion at 15q13.3 was detected in the father's blood. In case 2, NIPT showed a $1.5 \mathrm{Mb}$ deletion at 22q11.21, but aCGH of amniocytes revealed a 1.377 Mb duplication rather than a $1.5 \mathrm{Mb}$ deletion at 22q11.21. Furthermore, aCGH analysis of the parental blood revealed a $647 \mathrm{~kb}$ deletion at $22 \mathrm{q} 11.21$ in the mother and a $2.8 \mathrm{Mb}$ duplication of $22 \mathrm{q} 11.21$ in the father.
\end{abstract}

Conclusions: Our findings not only highlight the significance of diagnostic testing following a positive cfDNA sequencing result but also the necessity for additional analytical and clinical validation before routine use in practice.

\section{Background}

Noninvasive prenatal testing (NIPT) by massively parallel sequencing of cell-free fetal DNA (cffDNA) fragments has already become a mainstream technology in conventional aneuploidy screening since it was introduced in 2011. The high accuracy in detecting fetal trisomies 21 , 18 and 13 has been widely verified in numerous studies, with both a sensitivity and a specificity of $>99 \%[1-3]$. NIPT for common chromosomal aneuploidies is used increasingly in clinical practical advances [4-7]. More recently, some companies and laboratories have expanded NIPT to cover a number of microduplication/

\footnotetext{
* Correspondence: yinaiwa@vip.126.com

†Yiming Qi and Jiexia Yang are co-first authors.

${ }^{1}$ Prenatal Diagnosis Centre, Guangdong Women and Children Hospital, Guangzhou 511400, Guangdong, China

${ }^{2}$ Maternal and Children Metabolic-Genetic Key Laboratory, Guangdong Women and Children Hospital, Guangzhou 511400, Guangdong, China
}

microdeletion syndromes caused by copy number variants (CNVs) [8], and Chen et al. [9] and Liang et al. [10] demonstrated that NIPT performed well in microduplication/microdeletion syndromes.

Microduplication/microdeletion syndromes (MMSs) caused by CNVs are relatively rare, accounting for $1-2 \%$ [11] of all newborn congenital abnormalities, but they often result in a severe burden for both families and society. The most common microdeletion, 22q11.2 deletion syndrome (known as DiGeorge syndrome (DS)) [12], is even more common than T18 and T13 combined $[13,14]$. Thus, early detection of these subchromosomal imbalances is important, as it will help identify high-risk pregnancies and offer the possibility of a confirmatory invasive diagnostic test. However, there is still much to know about the clinical utility and validity of this screening for CNVs, and most of these clinically relevant

(C) The Author(s). 2020 Open Access This article is licensed under a Creative Commons Attribution 4.0 International License, which permits use, sharing, adaptation, distribution and reproduction in any medium or format, as long as you give appropriate credit to the original author(s) and the source, provide a link to the Creative Commons licence, and indicate if changes were made. The images or other third party material in this article are included in the article's Creative Commons licence, unless indicated otherwise in a credit line to the material. If material is not included in the article's Creative Commons licence and your intended use is not permitted by statutory regulation or exceeds the permitted use, you will need to obtain permission directly from the copyright holder. To view a copy of this licence, visit http://creativecommons.org/licenses/by/4.0/ The Creative Commons Public Domain Dedication waiver (http://creativecommons.org/publicdomain/zero/1.0/) applies to the data made available in this article, unless otherwise stated in a credit line to the data. 
CNVs occur in pregnancies lacking ultrasound anomalies. Therefore, it is often an accidental discovery of NIPT.

Here, we provided some special conditions of maternal $\mathrm{CNV}$ false positives and false negatives using low coverage massively parallel sequencing. In these two cases, the cfDNA result was false positive because of maternal rearrangements and false negative because of NIPT limitation. Thus, NIPT is a screening test. These results not only highlight the significance of diagnostic testing following a positive cfDNA sequencing result but also the necessity for additional analytical and clinical validation before routine use in practice.

\section{Materials and methods \\ NIPT}

Whole blood samples of 5 to $10 \mathrm{~mL}$ from pregnant women were collected in EDTA tubes within $8 \mathrm{~h}$. Afterwards, JingXin Fetal Chromosome Aneuploidy (T21, T18, and T13) Testing Kits (CFDA registration permit No. 0153400300) were used to perform cfDNA extraction, library construction, quality control, and pooling. Then, a semiconductor sequencer, the JingXin BioelectronSeq 4000 System (CFDA registration permit NO. 20153400309), was used for DNA sequencing. Sequencing reads were filtered and aligned to the human reference genome (hg19) [1]. Fetal and maternal chromosome copy number variations $(\mathrm{CNVs})$ were classified with our modified Stouffer's z-score method as described previously [15]. Here, each chromosome with an absolute value of the $\mathrm{z}$-score greater than 3 was marked with chromosome aneuploidies or microdeletions/ microduplications [15].

\section{Array CGH}

Umbilical cord blood samples or amniotic fluid were collected from the fetuses. Peripheral blood $(5 \mathrm{~mL})$ was collected from each parent. Genomic DNA was extracted from the fetal samples and peripheral blood using the QIAamp Genomic DNA Blood Mini Kits (Qiagen, Hilden, Germany). The DNA samples were heated by fragmentation, labeled, and hybridized to the Agilent 4X44k microarray (Agilent Technologies, Inc., Santa Clara, CA, USA) according to the standard protocol. The data were analyzed by Agilent CytoGenomics software, version 2.7.22.0.

\section{Case presentation}

\section{Case 1}

Patient 1 was a 28 -year-old, gravida 1 para 0 woman whose elective triple marker screen revealed a low risk of trisomy 21/18/13. Nuchal translucency (NT) was 1.3 $\mathrm{mm}$ at 13 gestational weeks. However, with the help of prenatal ultrasound series monitoring, a mild echogenic bowel (grade 1) and hydramnios with amniotic fluid volume (AFV) $74 \mathrm{~mm}$ were noted at 28 gestational weeks. The patient's past medical history was significant only for Southeast Asian deletion $\alpha^{0}$-thalassemia $\left(-{ }^{\mathrm{SEA}}\right)$. Two months prior to pregnancy, she started taking 0.4 mg folic acid and calcium tablets. Furthermore, the social history of the patient was negative for alcohol, tobacco, and illicit drug use before/during pregnancy.

NIPT based on low coverage $(0.1 \times)$ whole-genome sequencing using an Ion Proton Sequencer (CapitalBio Technology Inc., Beijing) was performed at 28 gestational weeks, and it suggested that there was a $1.1 \mathrm{Mb}$ deletion, with a z-score of -10.76 , located at 21q21.1. The estimated fetal DNA concentration in the maternal plasma was $19.7 \%$ on analysis (Table 1 and Fig. 1a). To explore the precise details, umbilical cord blood samples were punctured at 29 gestational weeks for the aCGH analysis. However, the aCGH analysis revealed a $422 \mathrm{~kb}$ deletion at $15 \mathrm{q} 13.3$, rather than the $21 \mathrm{q} 21.1$ deletion (Fig. 2a).

After extensive counseling, the patient told us that her husband had a history of epilepsy, which made us reconsidered this result. We then collected the peripheral blood of the parents for aCGH analysis. The mother's blood showed a $1.1 \mathrm{Mb}$ deletion at 21q21.1. The father's blood showed the same deletion ( $422 \mathrm{~kb}$ deletion) at the region of $15 \mathrm{q} 13.3$ (Fig. $2 \mathrm{~b}$ and c).

As is routine practice, an ultrasound was conducted to monitor the developmental status of the fetus, and no obvious abnormalities were recorded. The parents decided to continue the pregnancy. A male baby $3160 \mathrm{~g}$ and $51 \mathrm{~cm}$ high was delivered at term with no phenotypic abnormalities, and the Apgar score was 9 at $5 \mathrm{~min}$. As follow-up, the neonate was normal in growth and psychomotor development at 6 months of age.

\section{Case 2}

A 31-year-old, gravida 6 para 1 woman presented for prenatal counseling at 12 gestational weeks. First-trimester serum screening (FTS) indicated that the fetus was at intermediate risk of trisomy 21 syndrome (1/750) in another hospital. The woman had experienced three spontaneous abortions and one labor induction for intestinal malformation. She asked for NIPT at 13 gestational weeks due to FTS results and abnormal reproductive history. NIPT revealed a $1.5 \mathrm{Mb}$ deletion at $22 \mathrm{q} 11.21$, which overlaps the critical region of DiGeorge syndromes. The cffDNA was $14.7 \%$, and the z-score was -6.71 (Table 1 and Fig. $1 b$ ). Conventional cytogenetic analysis of cultured amniocytes revealed a normal karyotype of $46, \mathrm{XY}$ in all 40 cultured colonies. Then, aCGH was applied to the remaining uncultured amniocytes, and aCGH revealed a $1.377 \mathrm{Mb}$ duplication rather than a $1.5 \mathrm{Mb}$ deletion at $22 \mathrm{q}$ (Fig. 3a). The result of the fetus was arr[hg19] 22q11.21(1935464- 
Table 1 Summary of test results of NIPT and aCGH in this two cases

\begin{tabular}{|c|c|c|c|c|c|c|c|}
\hline \multirow[t]{2}{*}{ Case } & \multicolumn{4}{|l|}{ NIPT } & \multicolumn{3}{|l|}{ CMA } \\
\hline & cffDNA & CNV & $\begin{array}{l}z^{-} \\
\text {score }\end{array}$ & Reads & sample of fetus & $\begin{array}{l}\text { Peripheral blood of } \\
\text { mother }\end{array}$ & Peripheral blood of father \\
\hline $\begin{array}{l}\text { Case } \\
1\end{array}$ & $19.70 \%$ & $\begin{array}{l}1.1 \mathrm{Mb} \text { deletion } \\
\text { at } 21 \mathrm{q} 21.1\end{array}$ & -10.76 & $\begin{array}{l}4.29 \\
\mathrm{Mb}\end{array}$ & arr[hg19] 15q13.3(32021609-32444043)×1 & $\begin{array}{l}\text { arr[hg19] } \\
21 q 21.1(19731098- \\
20834451) \times 1\end{array}$ & $\begin{array}{l}\operatorname{arr}[\mathrm{hg} 19] \\
15 q 13.3(32021609- \\
32444043) \times 1\end{array}$ \\
\hline $\begin{array}{l}\text { Case } \\
2\end{array}$ & $14.70 \%$ & $\begin{array}{l}1.5 \mathrm{Mb} \text { deletion } \\
\text { at } 22 \mathrm{q} 11.21\end{array}$ & -6.71 & $\begin{array}{l}5.93 \\
\mathrm{Mb}\end{array}$ & arr[hg19] 22q11.21(18935464-20312661)×3 & $\begin{array}{l}\text { arr[hg19] } \\
22 q 11.21(20716876- \\
21363447) \times 1\end{array}$ & $\begin{array}{l}\text { arr[hg19] } \\
22 q 11.21(18636749- \\
21461017) \times 3\end{array}$ \\
\hline
\end{tabular}

20312661) ×3. Furthermore, aCGH analysis of the parental blood samples was performed to explore the real origin of the CNVs. It revealed the result of $\operatorname{arr}[\mathrm{hg19}$ $22 q 11.21(20716876-21363447) \times 1$, indicating a $647 \mathrm{~kb}$ deletion of $22 \mathrm{q} 11.21$ in the mother, and an $\operatorname{arr}[\mathrm{hg} 19]$ $22 q 11.21(18636749-21461017) \times 3$, indicating a $2.8 \mathrm{Mb} \mathrm{du}-$ plication of $22 \mathrm{q} 11.21$ in the father (Fig. $3 \mathrm{~b}$ and c); the area almost overlapped with the $\mathrm{CNV}$ of the fetus. Karyotypes were interpreted using the International System for Human Cytogenetic Nomenclature 2016 (ISCN 2016) criteria [16]. Continuous prenatal ultrasound monitoring and III level ultrasound screening at 24 gestational weeks did not find remarkable malformations. The location and volume of the fetal thymus and fetal echocardiogram were normal. A male infant with a weight of $2870 \mathrm{~g}$ and height of $46 \mathrm{~cm}$ was born at $37+{ }^{3}$ weeks with no phenotypic abnormalities, and the Apgar score was 8 at $5 \mathrm{~min}$.

\section{Discussion and conclusions}

Aneuploidy screening using cell-free DNA (cfDNA) has recently been expanded to include selected microdeletions. More recently, some companies and laboratories have expanded NIPT to detect MMSs caused by CNVs [8-10]. Expanding NIPT to include detection of specific conditions caused by a CNV [17] (such as 22q11.2 [18], 1p36 [19], cri-du-chat (5p15.3) [20], Prader-Willi (paternal 15q11-q13) [21] and Angelman (maternal 15q11-q13) [22]) is technically possible. However, validation has been limited, the sensitivity and specificity of detection of CNVs by NIPT are still unknown, and there are some special conditions where maternal CNV causes inconsistent results. In the present study, both cases were very special. False positives caused by maternal CNVs and false negatives simultaneously exist due to limitations of the technology. Thus, large sample clinical studies are still needed for its validation.

From 2015 to 2019, a total of 44,423 pregnant women underwent NIPT tests in our prenatal diagnostic center, with a total false positive number of 66 and a total false negative number of 2 . NIPT used in this study was performed by a semiconductor sequencing platform (SSP).

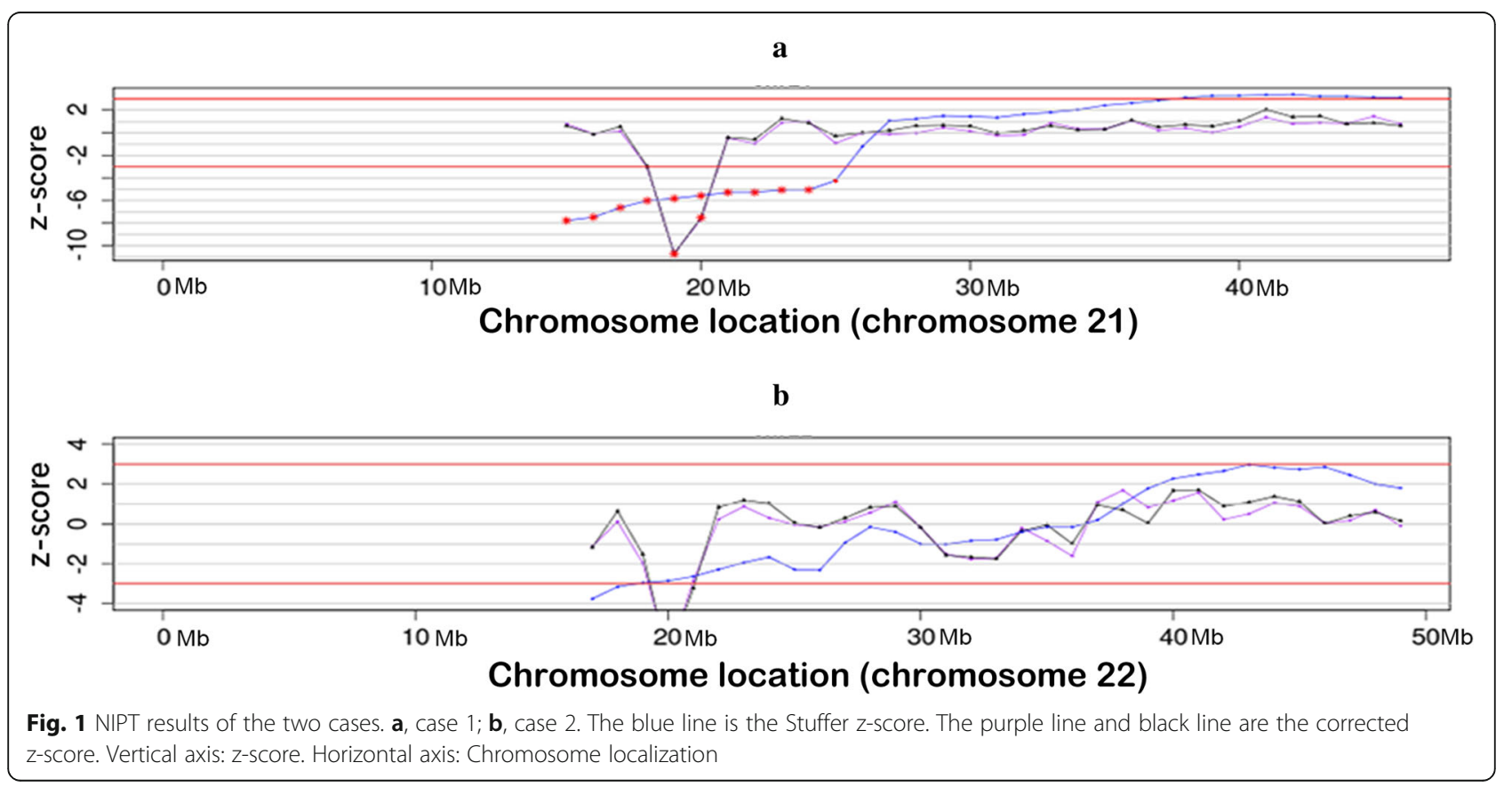




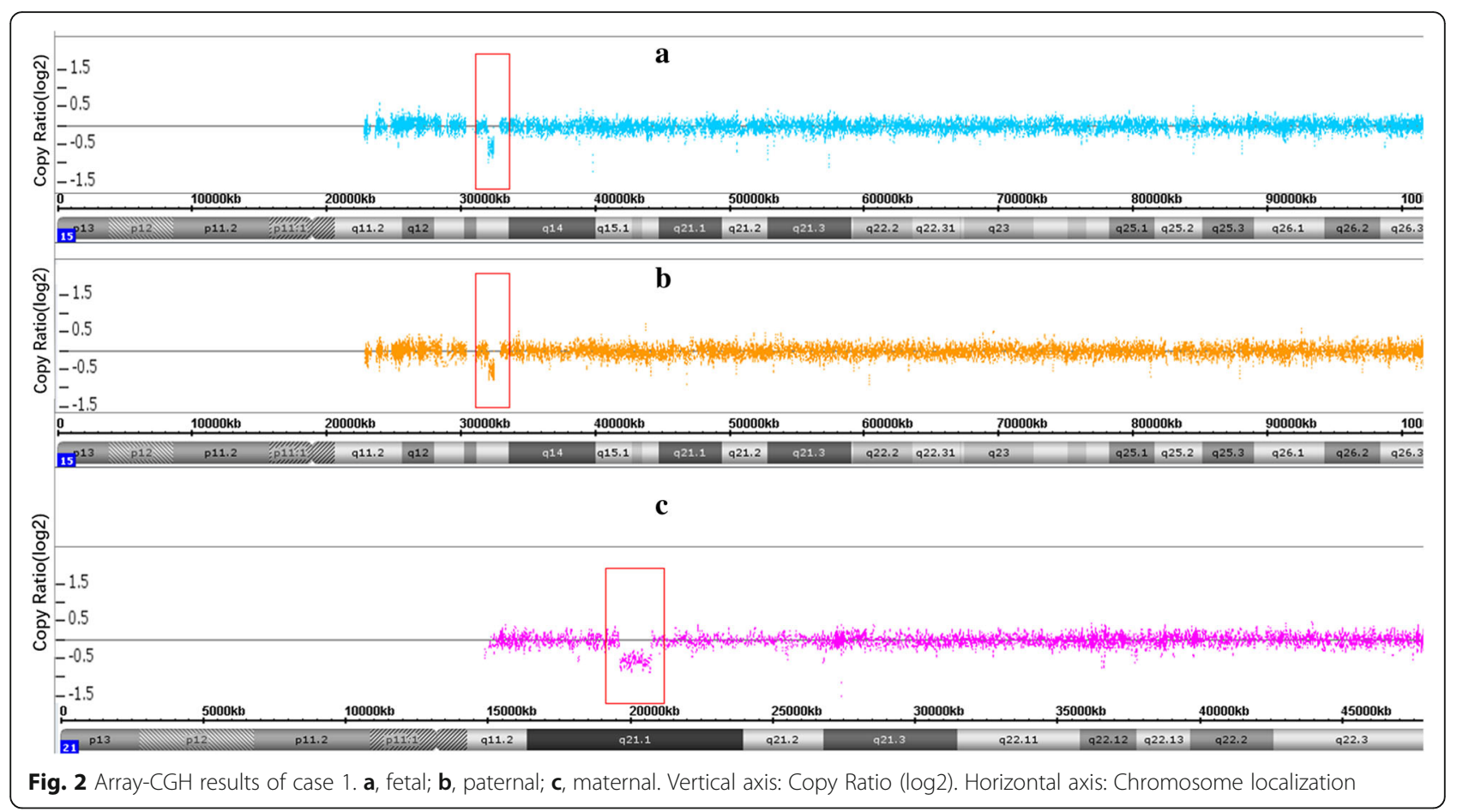

A previous study reported that the overall sensitivity and specificity of this platform for detecting trisomy 21, 18 and 13 combined were 99.61 and $99.91 \%$, respectively [1]. In addition, a recent study reported that NIPT performed well in detecting subchromosomal microdeletions/ microduplications with a large clinical sample size through this platform [8]. Moreover, we are exploring the detection of other chromosomal abnormalities using this platform [23]. However, NIPT is a screening test, and all the abnormal results underscore the need for additional validation

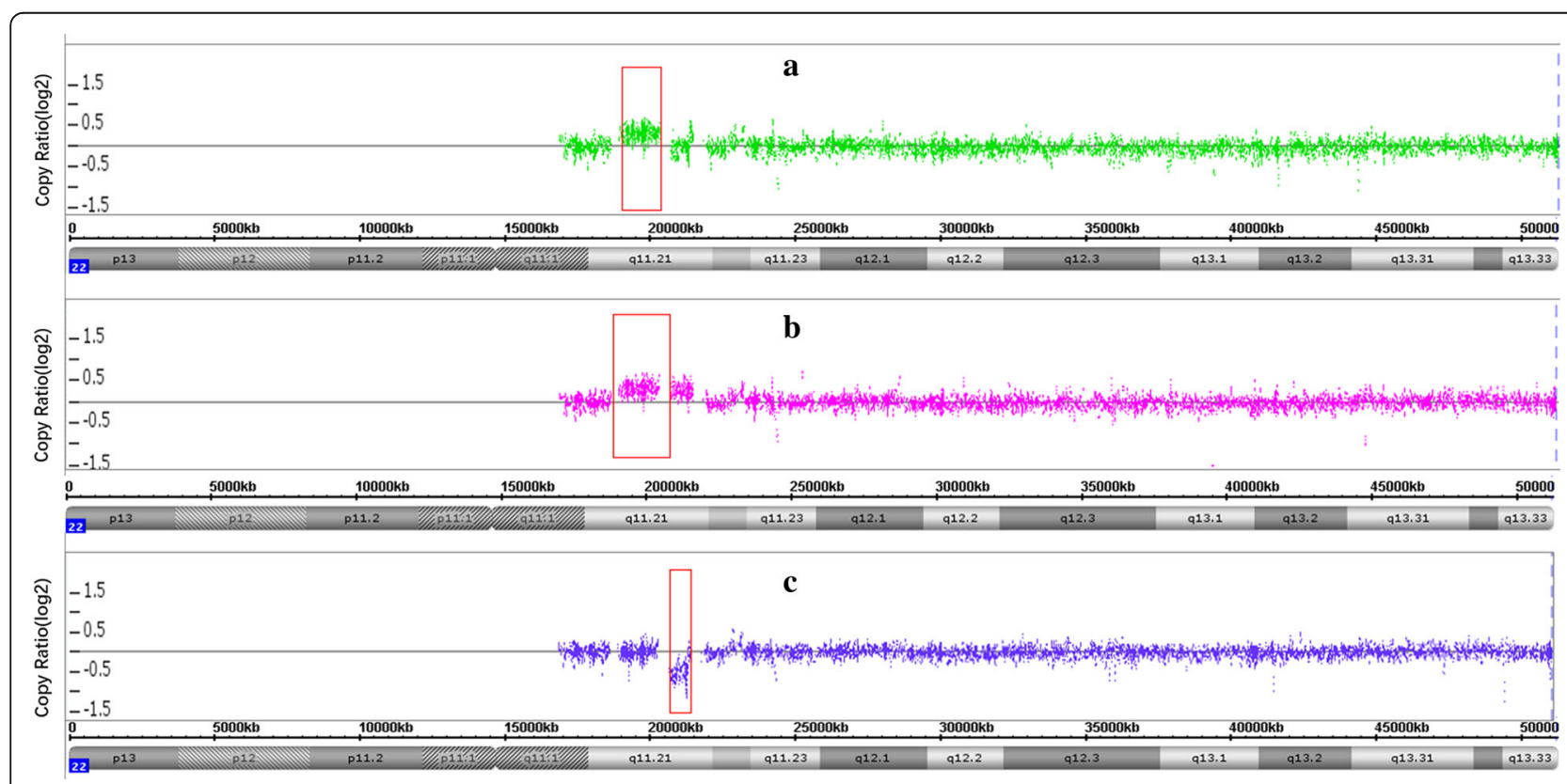

Fig. 3 Array-CGH results of case 2. a, fetal; b, paternal; c, maternal. Vertical axis: Copy Ratio (log2). Horizontal axis: Chromosome localization 
before routine use in practice as well as the necessity for confirmatory diagnostic testing after a positive cfDNA result.

The detection power of NIPT is determined mostly by fetal fraction, $\mathrm{CNV}$ size, and sequencing depth. Liao et al. [24] reported that at a mean fetal fraction of $14 \%$, for $\mathrm{CNVs}<5 \mathrm{Mb}$, the detection rate was only $14.3 \%$. For case 1 , the real fetal $\mathrm{CNV}$ sizes were $422 \mathrm{~kb}$. Even though the cffDNA was $19.7 \%$, exceeded $14 \%$, and the sequencing depth was $4.29 \mathrm{Mb}$, the chances of successful detection of CNVs of this size still approached zero. The results further demonstrated that CNV size is one of the most important factors influencing the detection rate of NIPT detecting chromosome microduplication/ microdeletion.

In case 1 , the father suffered from infantile-onset epilepsies 1 year after birth, although no obvious organic lesions, such as cortical malformations, tuberous sclerosis, and perinatal brain injury, were detected by brain magnetic resonance imaging (MRI). Congenital cardiac defects were not observed in the father, which might be attributed to the low penetrance of the 15q13.3 microdeletion for major structural abnormalities. As mentioned above, it is reasonable that the risk of epilepsy in the fetus is relatively high.

CNVs are an important source of normal and pathogenic variants. In case 2 , the fetus had a $1.377 \mathrm{Mb}$ duplication, the father had a $2.8 \mathrm{Mb}$ duplication on $22 \mathrm{q} 11.21$. The main clinical features of 22q11.2 duplication syndrome include hypocalcemia arising from parathyroid hypoplasia, thymic hypoplasia, and outflow tract defects of the heart (OMIM: 188400). The mother had a $647 \mathrm{~kb}$ deletion on 22q11.21. However, neither the mother nor the father seemed to have any abnormal clinical phenotype. Therefore, the parents decided to continue pregnancy. The CNV data in case 2 showed the amplification region on chr. 22 of the fetus, which was smaller than that in the father. One of the possibilities was that the fetus carried one chr. 22 from the father with the amplification and the second chr.22 with deletion from the mother. This meant that the possibility that the fetus had two CNVs on chr. 22 was high.

Positive detection results predicted by NIPT should be followed by diagnostic testing to confirm the fetal origin, as well as by parental studies to establish inheritance and to provide accurate counseling for patients.

\footnotetext{
Abbreviations

NIPT: Non-invasive prenatal testing; CNV: Copy-number variants; aCGH: ArrayCGH; DS: DiGeorge Syndrome; FTS: First-trimester serum screening; cfDNA: cell free DNA; NT: Nuchal Translucency; MMSs: Microduplication/ microdeletion syndromes; SSP: Semiconductor sequencing platform; MRI: Magnetic Resonance Imaging; AFV: Amniotic fluid volume;

-_-SEA: Southeast Asian deletion $a^{0}$-thalassemia; ISCN: International System for Human Cytogenomic Nomenclature
}

\section{Acknowledgements}

Not available.

\section{Authors' contributions}

All authors have materially participated in the study and manuscript preparation. Y.-m. Q. and J.-x. Y. collected all clinical data and drafted the manuscript; Y.-p. H., R. H., D.-m. W. carried out all the molecular genetic analyses; H.-s. P. participated in the data analysis; A.-h. Y. designed the work revised the manuscript. All authors have approved the final article.

\section{Funding}

The study was financially supported by the National Key Research and Development Program of China (2016YFC1000700, 2016YFC1000703 and Medical Scientific Research Foundation of Guangdong Province, China (B2017057). These funding supported us in completing the experiments, sequencing, data analysis, and publication.

\section{Availability of data and materials}

The datasets used and/or analyzed during the current study are available from the corresponding author on reasonable request.

\section{Ethics approval and consent to participate}

This study was approved by the Ethics Committee of Guangdong Women and Children Hospital (No.201601046).

\section{Consent for publication}

Obtained verbal consent for publication from the two pregnant women. They didn't mind reporting these genetic information to research, and they also signed a written consent form.

\section{Competing interests}

The authors declare that they have no competing interest.

Received: 17 January 2020 Accepted: 15 April 2020

Published online: 25 May 2020

References

1. Hu H, Liu H, Peng C, et al. Clinical experience of non-invasive prenatal chromosomal aneuploidy testing in 190,277 patient samples. Curr Mol Med. 2016;16(8):759-66

2. Mackie FL, Hemming $K$, Allen $S$, et al. The accuracy of cell-free fetal DNAbased non-invasive prenatal testing in singleton pregnancies: a systematic review and bivariate meta-analysis. BJOG. 2017;124(1):32-46.

3. Liang D, Lin Y, Qiao F, et al. Perinatal outcomes following cell-free DNA screening in >32 000 women: clinical follow-up data from a single tertiary center. Prenat Diagn. 2018;38(10):755-64.

4. Lefkowitz RB, Tynan JA, Liu T, et al. Clinical validation of a noninvasive prenatal test for genomewide detection of fetal copy number variants. Am J Obstet Gynecol. 2016;215(2):227.e1-227.e16.

5. Shaikh TH. Copy number variation disorders. Curr Genet Med Rep. 2017;5(4): 183-90.

6. Wapner RJ, Babiarz JE, Levy B, et al. Expanding the scope of noninvasive prenatal testing: detection of fetal microdeletion syndromes. Am J Obstet Gynecol. 2015;212(3):332.e1-9.

7. Fiorentino F, Bono S, Pizzuti F, et al. The clinical utility of genome-wide non invasive prenatal screening. Prenat Diagn. 2017;37(6):593-601.

8. Hu H, Wang L, Wu J, et al. Noninvasive prenatal testing for chromosome aneuploidies and subchromosomal microdeletions/microduplications in a cohort of 8141 single pregnancies. Hum Genomics. 2019;13(1):14.

9. Chen Y, Yu Q, Mao X, et al. Noninvasive prenatal testing for chromosome aneuploidies and subchromosomal microdeletions/microduplications in a cohort of 42,910 single pregnancies with different clinical features. Hum Genomics. 2019;13(1):60.

10. Liang D, Cram DS, Tan H, et al. Clinical utility of noninvasive prenatal screening for expanded chromosome disease syndromes. Genet Med. 2019; 21(9):1998-2006.

11. Wapner RJ, Martin CL, Levy B, et al. Chromosomal microarray versus karyotyping for prenatal diagnosis. N Engl J Med. 2012;367(23):2175-84.

12. Kruszka P, Addissie YA, McGinn DE, et al. 22q11.2 deletion syndrome in diverse populations. Am J Med Genet A. 2017;173(4):879-88. 
13. Oskarsdóttir S, Vujic M, Fasth A. Incidence and prevalence of the 22q11 deletion syndrome: a population-based study in Western Sweden. Arch Dis Child. 2004;89(2):148-51.

14. Francesca $R$, Denise $M$, Jose $C$, et al. Prevalence of recurrent pathogenic microdeletions and microduplications in over 9500 pregnancies. Prenat Diagn. 2015;35(8):801-9.

15. Yin A, Peng C, Zhao X, et al. Noninvasive detection of fetal subchromosomal abnormalities by semiconductor sequencing of maternal plasma DNA. Proc Natl Acad Sci U S A. 2015;112(47):14670-5.

16. Stevens-Kroef M, Simons A, Rack K, Hastings RJ. Cytogenetic nomenclature and reporting. Methods Mol Biol. 2017;1541:303-9.

17. Darius J. Adams, David a. common genetic and epigenetic syndromes. Pediatr Clin N Am. 2015;62(2):411-26.

18. Lorenzo D, Kristin M, Paul M, et al. A population-based study of the $22 q 11.2$ deletion: phenotype, incidence, and contribution to major birth defects in the population. Pediatrics. 2003;112(1):101-7.

19. Valerie K, Hitisha P, Daryl A, et al. 1p36 deletion syndrome: an update. Appl Clin Genet. 2015;8:189-200

20. Paola C. Cri Du chat syndrome. Orphanet J Rare Dis. 2006;1:33.

21. Suzanne B, Elisabeth D, Charles A, et al. Prader-Willi and Angelman syndromes: sister imprinted disorders [J]. Am J Med Genet. 2000;97(2):13646.

22. Kalsner $\mathrm{L}$, Chamberlain SJ. Prader-Willi, Angelman, and 15q11-q13 duplication syndromes. Pediatr Clin N Am. 2015;62(3):587-606.

23. Qi Y, Yang J, Hou Y, et al. The significance of trisomy 7 mosaicism in noninvasive prenatal screening. Hum Genomics. 2019;13(1):18.

24. Liao C, Yin A, Peng C, et al. Noninvasive prenatal diagnosis of common aneuploidies by semiconductor sequencing. Proc Natl Acad Sci U S A. 2014; 111(20):7415-20

\section{Publisher's Note}

Springer Nature remains neutral with regard to jurisdictional claims in published maps and institutional affiliations.

Ready to submit your research? Choose BMC and benefit from:

- fast, convenient online submission

- thorough peer review by experienced researchers in your field

- rapid publication on acceptance

- support for research data, including large and complex data types

- gold Open Access which fosters wider collaboration and increased citations

- maximum visibility for your research: over $100 \mathrm{M}$ website views per year

At $\mathrm{BMC}$, research is always in progress.

Learn more biomedcentral.com/submissions 